\title{
ODISEA, 10 AÑOS DESPUÉS
}

Desde que hace ya dos décadas se implantaran oficialmente en España los Estudios de Traducción, la disciplina ha florecido de manera extraordinaria, y hoy en día la demanda por parte de los estudiantes en las muchas Facultades, tanto públicas como privadas, existentes es realmente espectacular. Asimismo, mucho se ha progresado también en el ámbito profesional, en tanto las empresas e instituciones se van dando cuenta de la importancia de nuestros egresados en lugares tan importantes para la sociedad como los juzgados, los ministerios u organismos internacionales como la Unión Europea. Desde el punto de vista de la investigación, el avance ha llevado al área a emprender proyectos relacionados con el lado más creativo de la traducción, como puede ser el ámbito literario, pero asimismo otros que ponen sobre la mesa su cariz ideológico, puesto que la reflexión traductológica nos ha enseñado que traducir no es, ni mucho menos, limitarnos a buscar palabras en un diccionario, sino que, como dice George Steiner, los componentes semánticos se interrelacionan, a menudo aleatoriamente, como las moléculas en la superficie de un fluido. No hay dos lenguas, no hay dos dialectos o idiomas locales dentro de una lengua que identifiquen, designen, cartografíen sus mundos del mismo modo. Hablar una lengua es habitar, construir, registrar un entorno específico - una mundanidad, en el intenso sentido etimológico del término. Por eso Babel es todo lo contrario de una maldición. El don de lenguas es precisamente eso: un regalo y una bendición incalculables. La riqueza de la experiencia, la creatividad del pensamiento y del sentimiento, la penetrante y delicada singularidad de la concepción hecha posible por la condición políglota son el principal medio de adaptación y la principal ventaja del espíritu humano.

En este contexto de constante evolución, existen cada vez más publicaciones, monografías y revistas especializadas en el inabarcable campo de las filologías y de la traducción en España. Es evidente que el interés de los universitarios por dar a conocer los resultados de sus investigaciones ha traído consigo una gran cantidad de publicaciones periódicas. Unas se encuentran ya plenamente consolidadas y sus aportaciones son sinónimo de excelencia, excelencia que se ve reconocida en aquellos foros e instituciones donde la valoración objetiva redunda en el reconocimiento de los méritos académicos de los firmantes. Otras inician 
su andadura y tendrán aún que demostrar la solidez de su trayectoria en el transcurso del tiempo. En cualquiera de los casos, el trabajo que requiere la puesta en marcha de uno de estos medios a través de los cuales nuestras especialidades se ven beneficiadas es ingente. Se requiere una gran capacidad de trabajo y un ímprobo esfuerzo para mantener viva una revista en el actual panorama universitario español. Los responsables han de hacer frente a todo un cúmulo de burocracia que incluye las relaciones con los autores de los artículos, con los miembros del consejo editorial y con los lectores e informantes previos, por no mencionar los avatares derivados de las fuentes de financiación. Afortunadamente, este último extremo se amortigua en buena medida en las publicaciones digitales.

Revistas como Odisea pueden jactarse de tener tras de sí una ya prolongada trayectoria, diez años nada menos, y de querer emprender, sin embargo, caminos nuevos sin por ello desdeñar los ya transitados. Alcanzar el número 11, con otros tantos años de fructífera actividad, no es motivo más que de felicitación, siendo como es esta de las publicaciones, como se acaba de decir, una tarea nada fácil, colmada de obstáculos, especialmente cuando se tiende a la excelencia y al reconocimiento internacional. Sin duda estamos ante un caso ejemplar, digno de elogio y sobre todo de apoyo. Odisea quiere ahora hacer un guiño a un campo de investigación, apasionante donde los haya, que es el de la traducción, complementando de este modo el área temática de las Humanidades y convirtiéndose en una nueva vía para los estudiosos y traductólogos que abordan un terreno que se inmiscuye en la vida misma: porque traducir es amar el lenguaje y la existencia. Cada acto de nuestra vida es una traducción, una re-presentación de la realidad, una interpretación de lo que el otro nos quiere transmitir, un hacer con las palabras para hacerlas explotar, y para que, así, lo no verbal aparezca en lo verbal.

Odisea ha sabido adaptarse a las nuevas situaciones planteadas por la era de la globalización, a las nuevas tecnologías y a lo que hoy en día significa el lenguaje. Seguro que, en esa misma línea de constante superación, será a partir de ahora un referente tanto para los estudios filológicos como para los de traducción. En ambos casos, estoy segura de que Odisea, a través de unas investigaciones cuidadosamente evaluadas y seleccionadas, sabrá reflexionar sobre cómo viaja el significado; sabrá liberar todas las posibilidades del signo para pensar lo mismo de otra manera, respetando la diferencia y la dimensión de la otredad.

Desde estas páginas introductorias quiero expresar mis mejores deseos para el futuro de una revista que es ya de referencia obligada entre quienes nos dedicamos a investigar el lenguaje en todas sus privilegiadas manifestaciones.

\author{
$\mathrm{M}^{\mathrm{a}}$ Carmen África Vidal Claramonte \\ Catedrática de Traducción e Interpretación \\ Universidad de Salamanca
}

Odisea, $n^{\circ} 11$, ISSN 1578-3820, 2010, V-VI 